\title{
Betulinic acid enhanced the chemical sensitivity of esophageal cancer cells to cisplatin by inducing cell pyroptosis and reducing cell stemness
}

\author{
Jie Chen ${ }^{1}$, Ruirui Peng ${ }^{1}$, Zhaoxia Niu', Huicong Zhou ${ }^{2}$, Chunyan Kang ${ }^{3}$ \\ ${ }^{1}$ Department of Pathophysiology, Henan Medical College, Zhengzhou, China; ${ }^{2}$ Department of Digestion, The Second Affiliated Hospital of \\ Zhengzhou University, Zhengzhou, China; ${ }^{3}$ Department of Pathology, Henan Medical College, Zhengzhou, China \\ Contributions: (I) Conception and design: J Chen, C Kang; (II) Administrative support: J Chen, R Peng, Z Niu; (III) Provision of study materials or \\ patients: J Chen, H Zhou, C Kang; (IV) Collection and assembly of data: All authors; (V) Data analysis and interpretation: J Chen, R Peng, C Kang; \\ (VI) Manuscript writing: All authors; (VII) Final approval of manuscript: All authors. \\ Correspondence to: Chunyan Kang. Department of Pathology, Henan Medical College, No. 8 Shuanghu Road, Longhu Town, Zhengzhou, China. \\ Email: kangchunyan17@126.com.
}

Background: Betulinic acid (BA) is a lupine pentacyclic triterpene compound derived from the bark of the white mulberry tree, which has a variety of pharmacological properties. The purpose of this study was to investigate the effects of BA combined with cisplatin on the proliferation, stemness, pyroptosis, and xenograft growth of esophageal carcinoma cells in a nude mouse xenograft model.

Methods: The cell survival rate was detected by CCK- 8 method. TE-11 cells were treated with $3 \mu M$ of BA and $15 \mu \mathrm{M}$ of cisplatin. The cells were randomly divided into four groups: the control group, the BA group, the cisplatin group, and the BA + Cisplatin group. Western blotting was used to detect the expression levels of Ki67, PCNA, SOX2, OCT4, ASC, and Caspase-1. The xenograft model of nude mice was constructed to detect tumor volume, and the positive expression rates of Ki67 and Caspase-1 were detected by immunohistochemistry.

Results: Compared with the control group, Ki67, PCNA, SOX2, and OCT4 levels in the BA and cisplatin groups were significantly lower $(\mathrm{P}<0.05)$, while ASC and Caspase-1 levels were significantly higher $(\mathrm{P}<0.05)$. Compared with the BA group, Ki67, PCNA, SOX2, and OCT4 levels in the BA + cisplatin group were significantly lower $(\mathrm{P}<0.05)$, while ASC and Caspase-1 levels were significantly higher $(\mathrm{P}<0.05)$. In the nude mouse xenograft model, compared with the control group, the tumor volume of the BA and cisplatin groups was significantly decreased $(\mathrm{P}<0.05)$, the expression rate of Ki67 was significantly decreased $(\mathrm{P}<0.05)$, and the expression rate of Caspase- 1 was significantly increased $(\mathrm{P}<0.05)$. Compared with the $\mathrm{BA}$ group, the levels of ASC and Caspase-1 in the BA + cisplatin group were significantly lower $(\mathrm{P}<0.05)$, the positive expression rate of Ki67 was significantly lower $(\mathrm{P}<0.05)$, and the positive expression rate of Caspase-1 was significantly higher $(\mathrm{P}<0.05)$.

Conclusions: BA enhances the chemical sensitivity of esophageal cancer cells to cisplatin by inhibiting cell proliferation, reducing cell stemness, and inducing pyroptosis.

Keywords: Esophageal cancer; betulinic acid (BA); cisplatin; stemness

Submitted Mar 09, 2020. Accepted for publication Apr 26, 2020.

doi: 10.21037/apm-20-867

View this article at: http://dx.doi.org/10.21037/apm-20-867 


\section{Introduction}

Esophageal cancer, a gastrointestinal cancer, is placed eighth and sixth for incidence and mortality among all types of cancer, respectively (1). The symptoms of earlystage esophageal cancer patients often go undetected, and in moderate patients dysphagia is a typical symptom (2). As a result, the majority of patients are in the middle or late stages of esophageal cancer by the time they are admitted to hospital (3). The extremely high mortality and morbidity of esophageal cancer pose huge medical challenges. In clinical treatment, the most common therapy for patients with esophageal cancer is the combination of cisplatin with 5 -fluorouracil, although the therapeutic effects are often unsatisfactory, largely because of multidrug resistance (4). Therefore, the discovery of an effective way to reduce the multidrug resistance of tumors by enhancing the sensitivity of cancer cells to chemotherapeutic drugs has become one of the hot spots in the field of cancer treatment research.

Betulinic acid (BA) is a lupine pentacyclic triterpene compound extracted from white mulberry bark. It is reported to possess a variety of pharmacological properties, with antitumor, antimalarial, antiviral, anti-inflammatory, and antioxidant effects (5-7). Studies have indicated that BA has a strong inhibitory effect on esophageal cancer cells (8), and that it could be used in combination with antitumor drugs to induce tumor cell pyroptosis and inhibit tumor proliferation (9). BA is expected to be used as a synergist in combination with chemotherapy to avoid the development of multidrug resistance and enhance the therapeutic effect of antitumor drugs. Currently, no research has been carried out on the combination of BA and cisplatin to treat esophageal cancer. This study aimed to explore the effects of BA combined with cisplatin on the proliferation, dryability stemness, pyroptosis and growth of esophageal carcinoma cells in a nude mouse xenograft model.

\section{Methods}

\section{Test drugs and main reagents}

BA (B8936) was purchased from Sigma-Aldrich (SigmaAldrich, USA), with a chemical formula of $\mathrm{C} 30 \mathrm{H} 48 \mathrm{O} 3$, a molecular weight of 456.70 , and a purity $\geq 98 \%$. Cisplatin (C2210000) was purchased from Sigma-Aldrich (USA), with a chemical formula of $\mathrm{Pt}\left(\mathrm{NH}_{3}\right)_{2} \mathrm{Cl}_{2}$ and a molecular weight of 300.05. Roswell Park Memorial Institute 1640 medium (RPMI 1640) (61870-127), fetal bovine serum (26400-036), penicillin-streptomycin (15140-122), and trypsin (25200-056) were obtained from Gibco (USA). A CCK-8 kit (C0037) was purchased from Biyuntian Biotechnology Research Institute (Shanghai, China). Antibodies for anti-Ki67 (ab15580), PCNA (ab18197), SOX2 (ab97959), OCT4 (ab18976), ASC (ab180799), Caspase-1 (ab207802), cleaved Caspase-1 (ab2302), GAPDH (ab37168) were purchased from Abcam (Abcam, USA).

\section{Cell culture}

Human esophageal squamous cell lines (TE-11) were obtained from the American Type Culture Collection (ATCC). The cells were cultured in RPMI 1640 medium supplemented with $10 \%$ fetal bovine serum and $1 \%$ penicillin-streptomycin and incubated at $37^{\circ} \mathrm{C}$ in $5 \% \mathrm{CO}_{2}$. The medium was changed every $24 \mathrm{~h}$ during the cultivation process, and cells were passaged at the rate of 1:2. Cells in the logarithmic growth phase were selected for further experimentation.

\section{CCK-8}

After incubation for $24 \mathrm{~h}$, TE-11 cells were seeded into 96well plates $(100 \mu \mathrm{L} /$ well), and different concentrations of BA $(0.5,1,1.5,3,6,15,30$, and $50 \mu \mathrm{M})$ and cisplatin $(1,2.5,5$, $7.5,15,30,50,100$, and $200 \mu \mathrm{M})$ were added to the medium. Then, CCK-8 solution was added to the plate $(10 \mu \mathrm{L} /$ well $)$, and the cells were incubated for $4 \mathrm{~h}$, before the OD value was measured with a microplate reader at $450 \mathrm{~nm}$.

\section{Cell processing and grouping}

TE-11 cells in the logarithmic growth phase were treated with $3 \mu \mathrm{M}$ of BA (10) and $15 \mu \mathrm{M}$ of cisplatin and randomly divided into four groups: the control group, the BA group, the cisplatin group, and the $\mathrm{BA}+$ cisplatin group.

\section{Western blotting}

Each group of cells was treated with lysis buffer containing protease inhibitor on ice. A BCA kit was used to measure the total protein concentration. An equal amount of protein samples was extracted from each group of cells and denatured at $100{ }^{\circ} \mathrm{C}$ for $5 \mathrm{~min}$. Then, proteins were separated by running SDS-PAGE gel and then transferred to PVDF membranes. The membranes were blocked with $5 \%$ BSA at room temperature for $1-2 \mathrm{~h}$, before incubation 
with primary antibody for Ki67, PCNA, SOX2, OCT4, ASC, cleaved Caspase- 1 and Caspase- 1 at $4{ }^{\circ} \mathrm{C}$ overnight. The next day, the membranes were washed, HRPconjugated secondary antibody was added, and incubation took place at room temperature for $1 \mathrm{~h}$. After washing completely, ECL reagent was added to detect the intensity of chemiluminescence, and the exposure was photographed on a gel imager. Relative protein expression was calculated using ImageJ software, according to the gray value, with GAPDH used as a loading control. The experiments were conducted independently in triplicate.

\section{Establishment of a nude mouse xenograft model}

Twenty male 7-8 weeks old Balb/c nude mice (weight: $20 \pm 2 \mathrm{~g}$ ) were purchased from Beijing Weitong Lihua Animal Technology Co., Ltd. [license number: SCXK (Beijing) 20150001]. All of the mice were raised under specific-pathogenfree conditions. The mice were randomly divided into four groups: the control group, the BA group, the cisplatin group, and the $\mathrm{BA}+$ cisplatin group. TE-11 cells in the logarithmic growth phase were digested, and the cell concentration was adjusted to $2 \times 10^{7}$ cells per $0.1 \mathrm{~mL}$. Then, $0.2 \mathrm{~mL}$ of the cell suspension was injected into the right armpit of the nude mice. After 15 days, when the tumor reached approximately $1 \mathrm{~cm}$ in diameter, the model was indicated to be successful and the follow-up experiments were performed. BA at a dose of $50 \mathrm{mg} / \mathrm{kg}$ was intragastrically administered to the BA group. The administration concentration refered to the previous literature (11). The cisplatin group was intraperitoneally injected with cisplatin at $10 \mathrm{mg} / \mathrm{kg}$. The administration concentration refered to the previous literature (12). The BA + cisplatin group mice were intragastrically administered $50 \mathrm{mg} / \mathrm{kg}$ of BA and intraperitoneally injected with cisplatin $10 \mathrm{mg} / \mathrm{kg}$. An equal volume of normal saline was performed by intragastrically and intraperitoneally injection for 30 days in Control group.

\section{Tumor volume measurement}

From day 5 after the model was constructed, the major and minor diameters of the tumors were measured and recorded every 3 days. The formula was: tumor volume $=$ major diameter $\times$ minor diameter ${ }^{2} \times 1 / 2$.

\section{Immunobistochemistry}

The tumor tissue, embedded in paraffin was sectioned and routinely dewaxed. The tissue sections were incubated with 3\% hydrogen peroxide for 10 minutes at room temperature, and then placed in a container containing citrate buffer solution for about 10 minutes at $95{ }^{\circ} \mathrm{C}$, before being cooled at room temperature. Then, the sections were washed 3 times with PBS and blocked in $5 \%$ BSA solution at $37{ }^{\circ} \mathrm{C}$ for $30 \mathrm{~min}$. Primary antibody was added, and the sections were incubated at $37^{\circ} \mathrm{C}$ for $1 \mathrm{~h}$. After washing 3 times with PBS, the sections were incubated with biotin-labeled antibody at $37{ }^{\circ} \mathrm{C}$ for $30 \mathrm{~min}$. Next, the sections were once again washed 3 times with PBS and then incubated with $\mathrm{SABC}$ at $37^{\circ} \mathrm{C}$ for $30 \mathrm{~min}$. Finally, after washing with PBS 3 more times, the reaction was developed with diamino-benzidine (DAKO, Glostrup, Denmark). The sections were counterstained with hematoxylin (DAKO, Glostrup, Denmark), and then transparently dehydrated and mounted with neutral balsam. The proportion of positively stained cells was analyzed with ImageJ software.

\section{Statistical analysis}

Data analysis was carried out using SPSS 17.0 software, and the data were expressed as mean \pm standard deviation. The statistical significance of difference in vitro and in vivo data was analyzed by $t$-test. $\mathrm{P}<0.05$ considered to be statistically significant.

\section{Results}

\section{The cell survival rate of TE-11 cells was decreased after $B A$ and cisplatin treatment}

The cell viability of TE-11 cells treated with BA at different concentrations was detected by CCK- 8 . Compared with the 0.5 $\mu \mathrm{M}$ dose treatment, the cell survival rates at the doses of 6,15 , 30 , and $50 \mu \mathrm{M}$ were significantly reduced $(\mathrm{P}<0.05$; Figure $1 A)$. CCK-8 was used to detect the cell survival rates of TE-11 cells treated with cisplatin at different concentrations, and showed that the cell survival rate of the $30,50,100$, and $200 \mu M$ doses was significantly decreased compared with the dose of $1 \mu \mathrm{M}(\mathrm{P}<0.05$; Figure $1 B)$. To further determine the optimal dosing concentration, the effect of co-administration of Betulinic Acid and Cisplatin on cell viability was examined. As shown in Figure 1C, $3 \mu \mathrm{M}$ Betulinic Acid and $15 \mu \mathrm{M}$ Cisplatin were the optimal combination and the combination was used in subsequent experiment.

\section{Ki67 and PCNA protein levels in TE-11 cells treated with $B A$ combined with cisplatin were downregulated}

The Ki67 and PCNA protein expression levels in each 


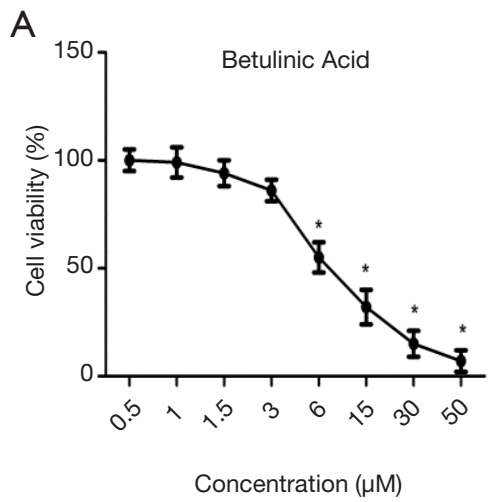

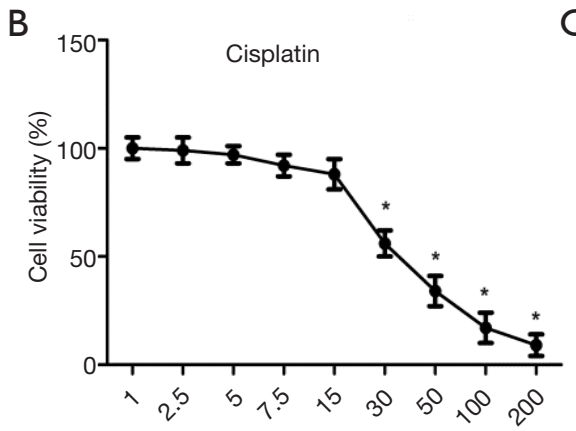

Concentration $(\mu \mathrm{M})$

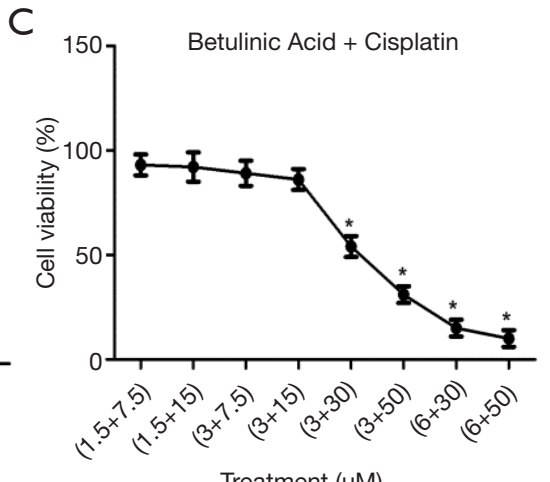

Treatment $(\mu \mathrm{M})$

Figure 1 The effects of betulinic acid and cisplatin on cell viability in TE-11 cells. (A) Cell viability of Betulinic Acid treated groups; (B) cell viability of Cisplatin treated groups; $(\mathrm{C})$ cell viability of Betulinic Acid + Cisplatin treated groups. Compared with the control group, ${ }^{*} \mathrm{P}<0.05$.

A

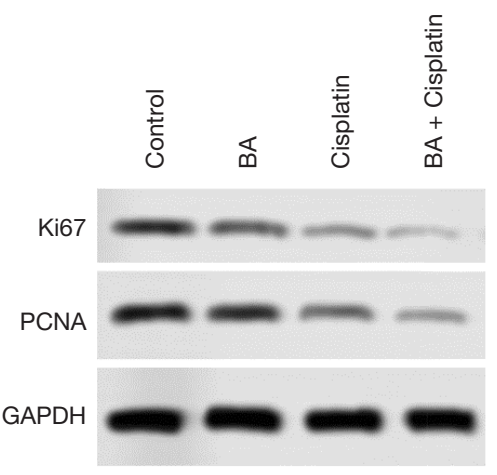

B

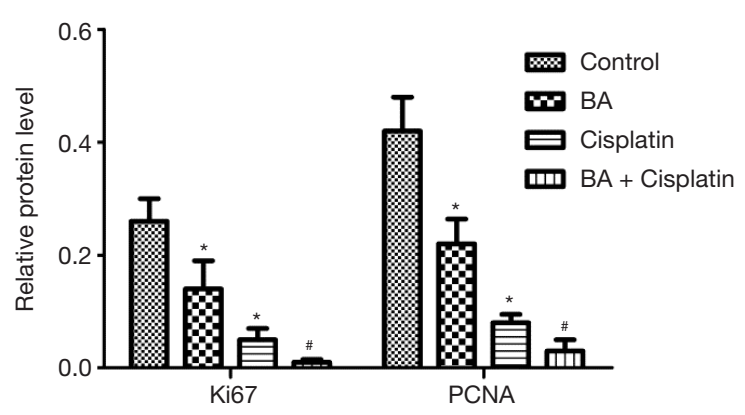

Figure 2 The protein expression levels of Ki67 and PCNA in TE-11 cells were downregulated by betulinic acid combined with cisplatin. (A) Western blot typical images; (B) relative protein level of Ki67 and PCNA. Compared with the control group, ${ }^{*} \mathrm{P}<0.05$; compared with BA group, ${ }^{\#} \mathrm{P}<0.05$.

group were detected by Western blotting. The protein levels of Ki67 and PCNA were significantly lower in the $\mathrm{BA}$ and cisplatin groups than in the control group $(\mathrm{P}<0.05)$. Ki67 and PCNA protein levels in the BA + cisplatin group were significantly lower than those in the $\mathrm{BA}$ group $(\mathrm{P}<0.05$; Figure 2).

\section{SOX2 and OCT4 protein levels and percentage of CD133+ cells in TE-11 cells treated with BA combined with cisplatin were downregulated}

The protein expressions of SOX2 and OCT4 in each group were analyzed by Western blotting (Figure $3 A$ ). The SOX2 and OCT4 protein levels were significantly lower in the $\mathrm{BA}$ and cisplatin groups compared with the control group
$(\mathrm{P}<0.05$; Figure $3 B)$. The levels of SOX2 and OCT4 were significantly lower in the $\mathrm{BA}+$ cisplatin group than in the BA group $(\mathrm{P}<0.05$; Figure $3 B)$. As shown in Figure $3 C, D$, percentage of CD133+ cells was decreased dramatically after treated by $\mathrm{BA}+$ cisplatin treatment $(\mathrm{P}<0.05)$.

\section{ASC and Caspase-1 protein levels in TE-11 cells treated with BA combined with cisplatin were downregulated}

The protein levels of ASC and Caspase- 3 in each group were tested by Western blotting (Figure $4 A$ ). The BA and cisplatin groups had higher protein levels of ASC and Caspase-3 compared with the control group $(\mathrm{P}<0.05$; Figure $4 B)$. The levels of ASC and Caspase- 3 in the BA + cisplatin group were significantly higher than those in the BA group 
A
B

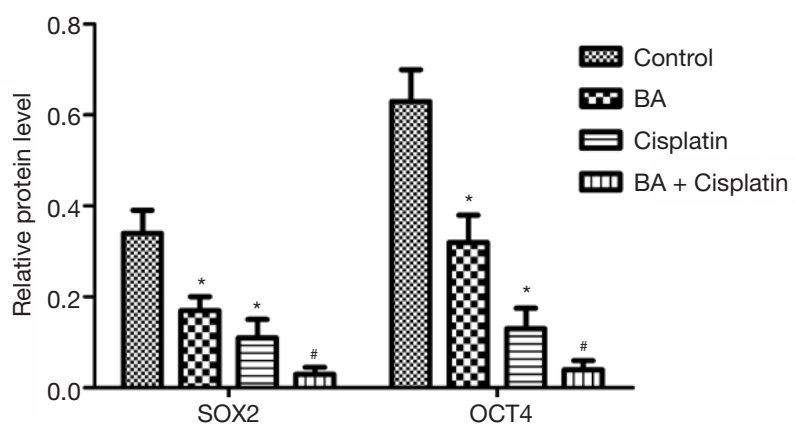

C

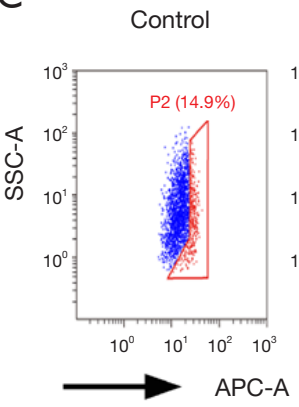

BA

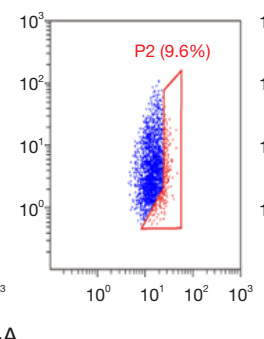

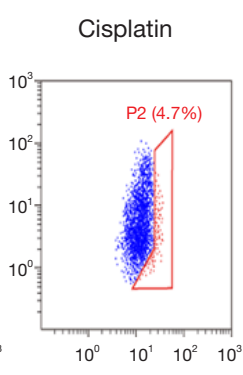

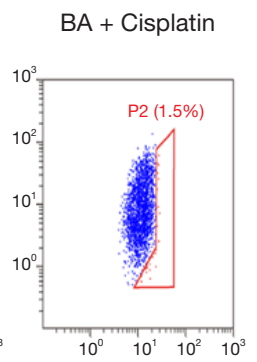

$\mathrm{D}$

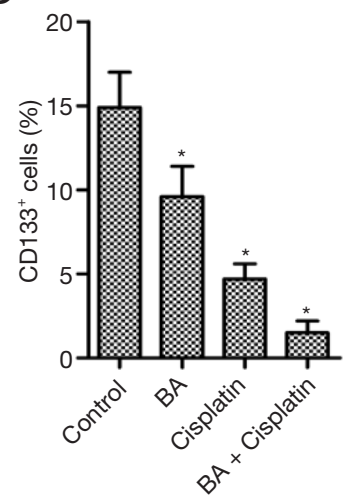

Figure 3 The expression levels of SOX2 and OCT4 in TE-11 cells were downregulated by betulinic acid combined with cisplatin. (A) Western blot typical images; (B) relative protein level of SOX2 and OCT4; (C) flow cytometry for the determination of CD133 activities; (D) percentage of $\mathrm{CD} 133^{+}$cells under four groups. Compared with the control group, ${ }^{*} \mathrm{P}<0.05$; compared with $\mathrm{BA}$ group, ${ }^{*} \mathrm{P}<0.05$.

$(\mathrm{P}<0.05$; Figure 4B).

\section{Effects of BA and cisplatin on esophageal cancer in a nude mouse xenograft model}

The tumor volumes of each group of mice are shown in Figure 5 A. Compared with the control group, the tumor volume in the $\mathrm{BA}$ and cisplatin groups was significantly decreased $(\mathrm{P}<0.05)$, and the levels of ASC and Caspase- 1 in the $\mathrm{BA}+$ cisplatin group were significantly lower than those in the BA group $(\mathrm{P}<0.05)$. The expressions of Ki67 and Caspase-1 in esophageal cancer in nude mice were detected by immunohistochemistry (Figure $5 B$ ). It revealed that the Ki67 positive expression rate in the BA and cisplatin groups was significantly lower than that of the control group $(\mathrm{P}<0.05$; Figure $5 C)$, while the Caspase-1 positive expression rate was significantly higher than that of the control group $(\mathrm{P}<0.05$; Figure 5D). Compared with the BA group, the Ki67 positive expression rate in the $\mathrm{BA}+$ cisplatin group was significantly reduced $(\mathrm{P}<0.05$; Figure 5 C), while the Caspase-1 positive expression rate was significantly increased $(\mathrm{P}<0.05$; Figure $5 D)$.

\section{Discussion}

Esophageal cancer is a malignant tumor that carries a high mortality rate and poses a serious threat to the health and lives of patients, most of whom gradually develop resistance to radiotherapy and chemotherapy in the later stage of treatment. Considering the poor efficacy of single drugs in the treatment of esophageal cancer, the combination of two or three drugs is widely used in clinical practice. However, drug treatment often fails eventually, due to the development of drug resistance in tumor cells (13). Therefore, the study of the multidrug resistance mechanism of esophageal cancer and the discovery of effective drugs with low toxicity and side effects bear great significance. 
A

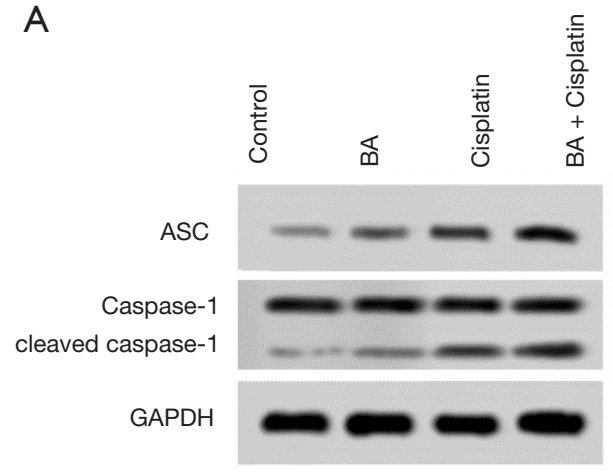

B

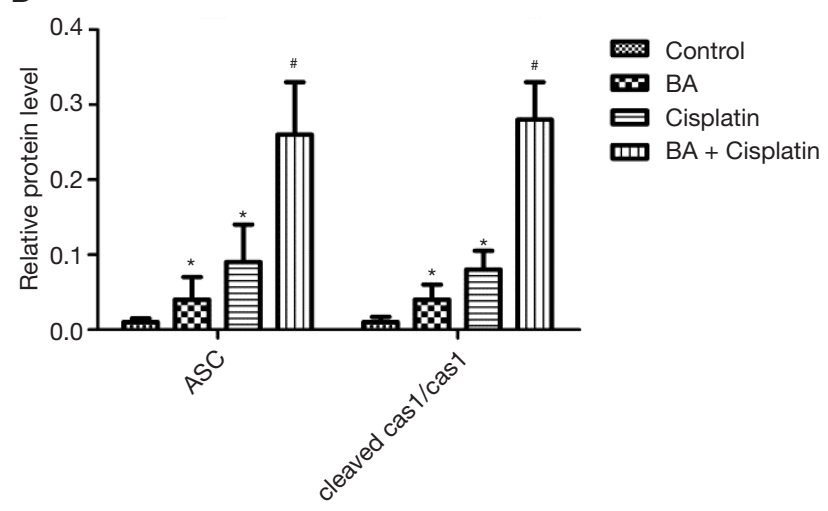

Figure 4 The effects of betulinic acid combined with cisplatin on the expression levels of ASC and Caspase-1 in TE-11 cells. (A) Western blot typical images; (B) relative protein level of ASC and cleaved cas1/cas1. Compared with the control group, ${ }^{*} \mathrm{P}<0.05$; compared with $\mathrm{BA}$ group, ${ }^{\#} \mathrm{P}<0.05$.

Esophageal cancer cells are highly malignant and exhibit strong proliferative activity. Inhibiting the proliferation of esophageal cancer cells is an important way of treating esophageal cancer Ki67. As a nuclear antigen of proliferating cells, it can reflect tumor proliferative activity, along with other tumor molecular markers, which is of great significance for judging tumor malignancy and prognosis, and for guiding postoperative adjuvant therapy (14). Lei et al. found that Ki67 was highly expressed in esophageal cancer and closely related to its occurrence and development (15). Existing in both normal cells and tumor cells, proliferating cell nuclear antigen (PCNA) is closely related to DNA synthesis and is highly expressed due to the strong proliferation ability of cancer cells (16). Pan et al. reported that BA could inhibit the proliferation of pancreatic cancer cells (PANC-1) (17). In this study, it was indicated that BA combined with cisplatin could downregulate the expression levels of Ki67 and PCNA in TE-11 cells, and reduce the tumor volume and the expression rate of Ki67 in an esophageal cancer model in nude mice, which suggests that BA combined with cisplatin can inhibit the proliferation of TE-11 cells and tumor development in nude mice.

There are some special cell subpopulations in tumor cells which show similar characteristics to stem cells, with the abilities of self-renewal, strong proliferation, and differentiation (18). Tumor stem cells greatly impact tumor invasion, relapse, and metastasis (19). SOX2 and OCT4, as cancer stem cells markers, play a vital role in maintaining stem cell pluripotency and are involved in tumor cell processes, including proliferation, differentiation, invasion, metastasis, drug resistance, and relapse (20). This study showed that BA combined with cisplatin downregulated the expression of SOX2 and OCT4 proteins in TE-11 cells and decreased the percentage of $\mathrm{CD} 133^{+}$cells, which suggests that BA combined with cisplatin can inhibit the stem-like characteristics of TE-11 cells.

Pyroptosis, as a new type of cell death, is widely involved in tumor occurrence and development (21). Decrease of cell death is one of the most important mechanisms in chemotherapy resistance, and so some chemotherapeutic drugs can increase the sensitivity of tumor cells to chemotherapy by inducing pyroptosis (22). The pathogenesis of pyroptosis depends on the formation and activation of typical inflammasomes, which are a multimeric protein complex comprising NLR family proteins, ASC, and Caspase- 1 precursors (23). This study found that BA combined with cisplatin could increase the expression of ASC and Caspase-1 protein in TE-11 cells as well as the positive expression rate of Caspase- 1 of esophageal carcinoma xenografts in nude mice, which indicates that BA combined with cisplatin can inhibit pyroptosis in TE-11 cells.

In summary, this study revealed the effects of BA combined with cisplatin on TE-11 cells, including the inhibition of cell proliferation, dry-like stemness characteristics, and pyroptosis, which also inhibited tumor formation of esophageal cancer in a nude mouse xenograft model. Therefore, this study provides a new basis for the clinical application of BA combined with cisplatin in the treatment of esophageal cancer. 
A

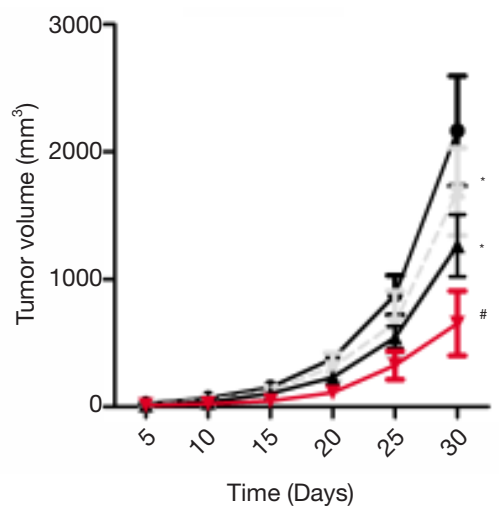

$\rightarrow$ Control

BA

$\mp$ Cisplatin

$\rightarrow$ BA + Cisplatin

B
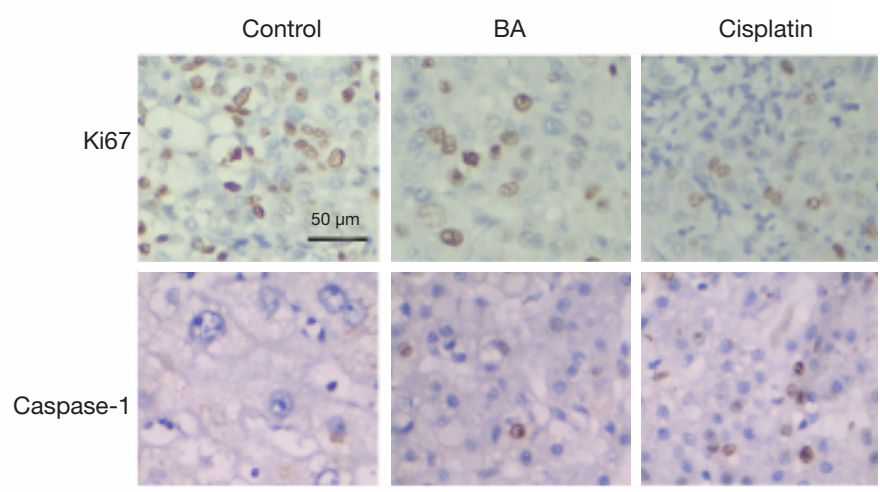

BA + Cisplatin

C
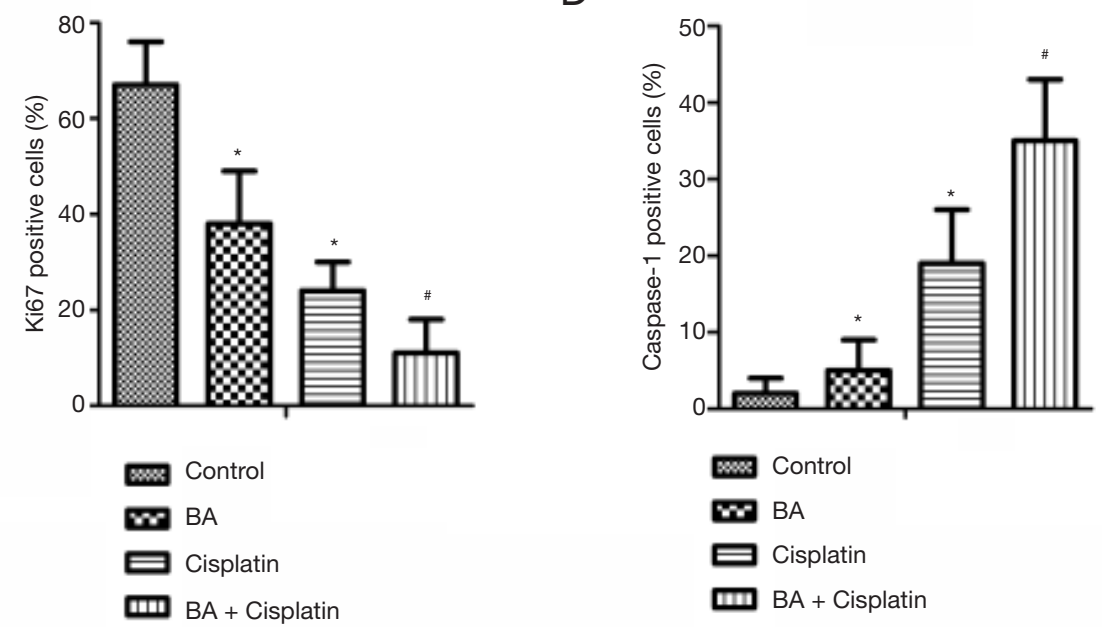

Figure 5 The effect of betulinic acid combined with cisplatin on esophageal cancer in a nude mouse xenograft model. (A) Tumor volume; (B) immunohistochemistry typical images; (C) percentage of Ki67 positive cells; (D) percentage of Caspase-1 positive cells. Compared with the control group, ${ }^{*} \mathrm{P}<0.05$; compared with $\mathrm{BA}$ group, ${ }^{*} \mathrm{P}<0.05$. 


\section{Acknowledgments}

Funding: This study was supported by the Science and Technology Project of Henan province (No. 192102310103).

\section{Footnote}

Data Sharing Statement: Available at http://dx.doi. org/10.21037/apm-20-867

Conflicts of Interest: All authors have completed the ICMJE uniform disclosure form (available at http://dx.doi. org/10.21037/apm-20-867). The authors have no conflicts of interest to declare.

Ethical Statement: The authors are accountable for all aspects of the work in ensuring that questions related to the accuracy or integrity of any part of the work are appropriately investigated and resolved. The study was approved by Henan Medical College.

Open Access Statement: This is an Open Access article distributed in accordance with the Creative Commons Attribution-NonCommercial-NoDerivs 4.0 International License (CC BY-NC-ND 4.0), which permits the noncommercial replication and distribution of the article with the strict proviso that no changes or edits are made and the original work is properly cited (including links to both the formal publication through the relevant DOI and the license). See: https://creativecommons.org/licenses/by-nc-nd/4.0/.

\section{References}

1. Torre LA, Bray F, Siegel RL, et al. Global cancer statistics 2012. CA Cancer J Clin 2015;65:87-108.

2. Hsu PK. The era of personalized multimodal treatments for esophageal cancer. Ann Transl Med 2018;6:75.

3. Zhang Z, Xu L, Di X, et al. A retrospective study of postoperative radiotherapy for locally advanced esophageal squamous cell carcinoma. Ann Palliat Med 2019;8:708-16.

4. Chuang J, Chao J, Hendifar A, et al. Checkpoint inhibition in advanced gastroesophageal cancer: clinical trial data, molecular subtyping, predictive biomarkers, and the potential of combination therapies. Transl Gastroenterol Hepatol 2019;4:63.

5. Wang W, Wang Y, Liu M, et al. Betulinic acid induces pyroptosis and suppresses metastasis in hepatocellular carcinoma cell lines in vitro and in vivo. J Cell Mol Med
2019;23:586-95.

6. Karagöz AÇ, Leidenberger M, Hahn F, et al. Synthesis of new betulinic acid/betulin-derived dimers and hybrids with potent antimalarial and antiviral activities. Bioorg Med Chem 2019;27:110-5.

7. Chen W, Liu D, Huang S. Betulinic acid attenuates high glucose-induced oxidative stress injury through PI3K/ Akt/Nrf2 signaling pathway. Chinese Journal of Diabetes 2019;27:917-21.

8. Zuco V, Supino R, Righetti SC, et al. Selective Cytotoxicity of Betulinic Acid on Tumor Cell Lines, But Not Normal Cells. Cancer Lett 2002;175:17-25.

9. Sawada N, Kataoka K, Kondo K, et al. Betulinic acid augments the inhibitory effects of vincristine on growth and lung metastasis of B16F10 melanoma cells in mice.Br J Cancer 2004;90:1672-8.

10. Kutkowska J, Strzadala L, Rapak A. Synergistic activity of sorafenib and betulinic acid against clonogenic activity of non-small cell lung cancer cells. Cancer Sci 2017;108:2265-72.

11. Lu P, Zhang CC, Zhang XM, et al. Down-regulation of NOX4 by betulinic acid protects against cerebral ischemiareperfusion in mice. J Huazhong Univ Sci Technol Med Sci 2017;37:744-9.

12. Ravichandran K, Holditch S, Brown CN, et al. IL-33 deficiency slows cancer growth but does not protect against cisplatin-induced AKI in mice with cancer. Am J Physiol Renal Physiol 2018;314:F356-66.

13. Nan P, Li C, Sun F, et al. Preliminary screening of chemotherapy-resistant genes in esophageal cancer and its clinical significance. Medical Journal of Chinese People's Liberation Army 2019;44:222-7.

14. Jia Z, Wang J, Yan B, et al. Correlation of Expression between P53 and Ki-67 in Digestive Tract Tumors and Its Clinical Significance. Friend of Chemical Industry 2015,34:51-2.

15. Lei L, Ye Bn, Wang X. Expression of P53, Ki67 in Esophageal Cancer and Its Clinical Significance. Guide of China Medicine 2014,12:10-2.

16. Tan J. Effects of CD47 Gene on the Proliferation of Esophageal Cancer Cells. Genomics and Applied Biology 2019;38:484-8.

17. Pan J, Zhou H, Wang G, et al. Inhibition of betulinic acid on pancreatic cancer cells and effects on $\beta$-catenin, Cyclin D1 and C-Myc proteins. Chinese Journal of Cancer Prevention and Treatment 2019;26:385-8.

18. Kondo T. Stem cell-like cancer cells in cancer cell lines. Cancer Biomark 2007;3:245-50. 
19. Yu X, Jiang X, Li H, et al. miR-203 inhibits the proliferation and self-renewal of esophageal cancer stemlike cells by suppressing stem renewal factor Bmi-1. Stem Cells Dev 2014;23:576-85.

20. Saigusa S, Tanaka K, Toiyama Y, et al. Correlation of CD133, OCT4, and SOX2 in rectal cancer and their association with distant recurrence after chemoradiotherapy. Ann Surg Oncol 2009;16:3488-98.

21. Wang Y, Yin B, Li D, et al. GSDME mediates Caspase-1dependent pyroptosis in gastric cancer. Biochem Biophys

Cite this article as: Chen J, Peng R, Niu Z, Zhou H, Kang C. Betulinic acid enhanced the chemical sensitivity of esophageal cancer cells to cisplatin by inducing cell pyroptosis and reducing cell stemness. Ann Palliat Med 2020;9(4):1912-1920. doi: 10.21037/apm-20-867
Res Commun 2018;495:1418-25.

22. Duan J, Xu H, Luo P, et al. DEPTOR improves cisplatin chemosensitivity in esophageal squamous cell carcinoma cells by inducing Caspase-1-mediated pyroptosis. Acta Pharmaceutica Sinica 2019;54:1845-50.

23. Cerqueira DM, Pereira MS, Silva AL, et al. Caspase-1 but not caspase-11 is required for NLRC4-mediated pyroptosis and restriction of infection by flagellated legionella species in mouse macrophages and in vivo. J Immunol 2015;195:2303-11. 